\title{
Effect of Mucuna Pruriens Seeds Supplementation on Physiological, Hemato-Biochemical, Antioxidant, Thyroid, and Progesterone Profile of Beetal Does in Relation to Seasonal Stress
}

Sameer Niwas Jadhav ( $\nabla$ sameerbiochem@gmail.com )

Guru Angad Dev Veterinary and Animal Sciences University https://orcid.org/0000-0002-8595-4449

Shashi Nayyar

Guru Angad Dev Veterinary and Animal Sciences University

Mrigank Honparkhe

Guru Angad Dev Veterinary and Animal Sciences University

Mandeep Singla

Guru Angad Dev Veterinary and Animal Sciences University

\section{Research Article}

Keywords:

Posted Date: January 25th, 2022

DOI: https://doi.org/10.21203/rs.3.rs-1237399/v1

License: (c) (1) This work is licensed under a Creative Commons Attribution 4.0 International License.

Read Full License 


\section{Abstract}

A study was conducted to analyze the effect of raw Mucuna pruriens seed supplementation on the physiological adaptability of Beetal goat does to seasonal stress. Supplementation with raw Mucuna pruriens seed powder was done at lower level of $100 \mathrm{mg} / \mathrm{kg}$ bodyweight for 30 days to beetal does during winter and summer season. Blood samples were collected on $0,15,30$ and 45 th day. Temperature humidity index was found higher $(83.08 \pm 0.35)$ during the summer season, while relative humidity remained high (63.77 \pm 2.32 ) during the winter season. Data analysis by Analysis of covariance (ANCOVA) revealed that compared to control, Mucuna pruriens supplementation in goats resulted in a significant decrease in heart rate during the summer season, increase in respiration rate in the winter season, decrease in overall glucose, cholesterol, creatinine, blood urea nitrogen, Erythrocytic lipid peroxidation (MDA) level and increase in packed cell volume, hemoglobin, total erythrocyte and leukocyte count, total protein, albumin, alkaline phosphatase, immunoglobulin, reduced glutathione and total antioxidant capacity levels indicating positive anabolic effect. A significant increase in plasma progesterone in Mucuna pruriens supplemented does compare to control was observed during winter season. It may be concluded that supplementation of raw Mucuna pruriens at lower levels were found to be efficient nutraceutical supplement option for does feeding and has a positive effect on amelioration of seasonal stress \& improvement in health and sustainability of Beetal does.

\section{Introduction}

Among abiotic stress, seasonal stress is the major constraint to animal production in tropical and subtropical regions. Seasonal stress causes direct and indirect losses to the livestock owners in terms of reduced growth, milk production, and reproductive performance of livestock (Rojas et al., 2017). Adaptive changes to heat stress include physiological, hormonal, hematological biochemical \& molecular responses (Ribeiro et al.,2018). Animal with better physiological adaptability can perform better during seasonal stress. Various interventions are done to manipulate \& boost the adaptive capacity of an animal to seasonal stress. Herbal feed additives containing bioactive compounds act as anti-stressors \& help to stabilize animal health status during seasonal stress. $M$. pruriens, a widely available leguminous plants in tropical countries, including India. The most available literature of $M$. pruriens in animals cites the use of processed M.prurien seeds as unconventional feedstuffs to utilize its nutrient content, especially crude proteins (20 to $30 \%$ ). Besides nutritional components, several bioactive compounds present in raw $M$. pruriens seeds are known to exhibit various medicinal and pharmacological properties (Natarajan et al., 2012). These include polyphenols, flavonoids, terpenoids, alkaloids, tannin, saponins, essential fatty acids, amino acids, and L-DOPA. Several beneficial effects of $M$ pruriens have been demonstrated in invitro and in-vivo studies in humans and laboratory animals (Misra and Wagner, 2007) which include mainly antistress, antidiabetic, antioxidant, and neuroprotective, cardioprotective, anticancerous, antimicrobial effect. This suggests that raw M.pruriens seeds can be a potential nutraceutical option for animal feeding. Daromala et al. (2015) reported that exposure of bucks to small quantities of $M$. prurien seed powder at $100 \mathrm{mg} / \mathrm{kg}$ Body wt administered via oral route for 30 days led to a significant increase in 
body weight gain, reproductive organ weight, and considerable improvement in spermiogram of buck. Based on the positive effects of low quantities of $M$ pruriens in male bucks, nutraceutical potential needs to be evaluated for use in adult females does. Considering this, present research work was conducted to study the efficacy of Mucuna pruriens seed powder supplementation on improving health and physiological adaptability of beetal does to seasonal stress. Various physiological, hematological, biochemical, antioxidant, hormonal parameters were compared between control, and M.prurien supplemented beetal does during winter and summer season.

\section{Material And Method}

Total 32 apparently healthy adult beetal does were used in the study. The study was conducted during the winter $(n=16)$ and summer $(n=16)$ seasons. Sixteen beetal does were divided into two groups viz control and M.pruriens supplemented (8 goats in each group).Does under control group were fed basal diet as per NRC recommendations. Does under-treatment groups were fed with a basal diet plus $100 \mathrm{mg} / \mathrm{kg}$ body weight (dose as per Doromala et al. 2015) of raw M. Pruriens powdered seeds / Animal/ day for 30 days. Blood \& serum samples were collected from two groups on 0,15 th, $30^{\text {th }}$, and 45 th day of the study period. For progesterone estimation, blood samples were collected from does during the study period on 0,10 and 20th day of the estrous cycle (day 0 being the day of estrous). RBC hemolysate was prepared as per (Saleh 2009) for antioxidant parameter testing. Plasma was separated for hormonal and total antioxidant capacity estimation. Environmental parameters viz temperature, relative humidity was recorded THI was calculated as per Tucker et al. (2008). Rectal temperature $\left({ }^{\circ} \mathrm{C}\right)$ by a digital thermometer, respiration rate (breaths/Min) by flank method, and heart rate (Beats/Min) by placing a stethoscope over the heart between left 4th to 5th intercostal space was recorded fortnightly as a physiological indicator of heat stress. Hematological parameters testing viz PCV by microhematocrit method, Hemoglobin by sahli's hemoglobinometer, total erythrocyte count (TEC) \& Total leukocyte count (TLC) by hemocytometer, differential leukocyte count (DLC) by leishman's staining was carried out from collected blood samples. Biochemical metabolites viz glucose, total proteins, albumin, globulin, total cholesterol, triglyceride, creatinine, bilirubin, blood urea nitrogen (BUN), and enzymes ALT, AST, ALP, GGT were estimated in serum samples by a semi-automated analyzer. Erythrocyte lipid peroxidation level, reduced glutathione, superoxide dismutase were done in RBC hemolysate. Total antioxidant capacity (TAC) was measured in plasma Hemoglobin in hemolysate was determined according to the method of Drabkin and Austin (1935). Hemoglobin concentrations were expressed in $\mathrm{mg} / \mathrm{ml}$ of hemolysate. Erythrocytic lipid peroxidation levels were determined by thiobarbituric acid reactive substance (TBARS) by MDA assay as per Placer et al. (1966). The concentration of reduced glutathione (GSH) was determined using the method of Ellman (1959). Erythrocytic superoxide dismutase activity (SOD) was determined as per Nishikimi et al. (1972). SOD activity was calculated using a correlation factor as per Zhang et al. (2016). Plasma total antioxidant activity was measured by ferric reducing antioxidant power (FRAP) assay as per Benzie and Szeto (1999). FRAP values were expressed as $\mu \mathrm{mol} / \mathrm{ml} \mathrm{FeSO4.7H2O} \mathrm{equivalent.} \mathrm{Total}$ immunoglobulin fraction was separated from plasma by using $45 \%$ saturated ammonium sulfate as per the method by Oser (1965). Total immunoglobulin (mg/dl) level in the separated fraction was estimated 
by the method of Lowry et al. (1951). T3 and Thyroxine (T4) were analyzed on 0 and 30th day plasma samples with commercially available C-ELISA kit ( Calbiotech). The sensitivity of T3 and T4 assay kit was $0.066 \mathrm{ng} / \mathrm{ml}$ and $3.20 \mathrm{ng} / \mathrm{ml}$, respectively. Quantitative estimation of plasma progesterone was done by DIAsource progesterone C-ELISA kit. The sensitivity of the assay kit was $0.057 \mathrm{ng} / \mathrm{ml}$. Statistical analyses for all measurements were performed using SPSS version 20.0 (IBM Corp., 2013). Effect of M.pruriens supplementation on various tested parameters was compared with control by using repeated measures analysis of covariance (ANCOVA) (15,30 \& 45th -day data) by controlling data for prefeeding day 0 as a baseline covariate. Data is represented as overall adjusted mean \pm SE of treatment group (M.pruriens supplemented) and control along with mean \pm SE of covariate (day 0 ). Degrees of freedom for group effect in repeated measure ANCOVA estimate was used to denote df1 and df2. A significant effect ( $p$ values) was indicated at 0.05 and 0.01 levels.

\section{Results}

\section{Environmental Parameters}

Average environmental temperature $\left({ }^{0} \mathrm{C}\right)$, relative humidity $\%$ and $\mathrm{THI}$ recorded during the study period were ranged from $12.91 \pm 0.26,78.66 \pm 1.28,55.60 \pm 0.43$ during the winter season to $37.10 \pm 0.68,29.83 \pm$ $1.39,83.08 \pm 0.35$ during the summer season, respectively. A climatic environment with an air temperature in the range of $13-27^{\circ} \mathrm{C}$, relative humidity of $60-70 \%$, and a THI of less than $65 \%$ is considered a comfort zone (Misra and Puneet,2009). During summer and winter, animals were found exposed to an ambient temperature or humidity beyond their comfort zone, which indicates that they were experiencing stress in both seasons while pronounced thermal stress exhibited by animals during the summer season.

\section{Effect of M.pruriens supplementation on physiological Parameters-}

Data of physiological parameters recorded in control and M.pruriens supplemented does have been graphically represented in Fig. 1 . The overall effect of $M$. pruriens on rectal temperature during both seasons in goats was found to be non-significant. M. pruriens supplementation significantly increased respiration rate (breaths $/ \mathrm{min}$ ) in winter season (Mean $\pm \mathrm{SE}$; Covariate 35.75 \pm 0.46; treatment 38.26 \pm 0.58 vs control $36.23 \pm 0.58), F_{(1,13)}=5.90, P<0.05$ after controlling day 0 values. The effect was non-significant during the summer season. $M$. pruriens supplementation significantly decreased heart rate (beats $/ \mathrm{min}$ ) during summer season (Mean $\pm S E$, Covariate $79.56 \pm 0.63$,treatment $79.92 \pm 0.84$ vs control $80.78 \pm 0.84$ ), $F_{(1,13)}=7.21, P<0.05$, while the effect was non-significant during the winter season.

\section{Effect of M.pruriens supplementation on hematological parameters-}

Data of hematological parameters have been graphically represented in Fig. 2. PCV \% (Mean \pm SE; covariate $31.29 \pm 0.48$, treatment $32.18 \pm 0.37$ vs control $31.18 \pm 0.42), \mathrm{F}_{(1,13)}=18.14, \mathrm{P}<0.01 ; \mathrm{Hb}$ concentration (Mean \pm SE; covariate $9.79 \pm 0.04$,treatment $9.97 \pm 0.05 v$ s control $9.77 \pm 0.05$ $\mathrm{g} / \mathrm{dl}), \mathrm{F}_{(1,13)}=7.02, \mathrm{P}<0.05$; TEC count $\left(\times 10^{6} \mathrm{Cells} / \mu \mathrm{l}\right)$ (Mean $\pm \mathrm{SE}$; covariate $9.35 \pm 0.22$,treatment $9.63 \pm 0.06$ 
vs control $9.43 \pm 0.06), F_{(1,13)}=5.11, P<0.05$ were significantly increased during winter season while TLC count $\left(\times 10^{3}\right.$ Cells $/ \mu$ l) (Mean \pm SE; covariate $10.60 \pm 0.13$,treatment $11.14 \pm 0.09$ vs control $10.42 \pm 0.09), F_{(1,29)}=22.72, P<0.01$; lymphocyte count $(\%)$ (Mean $\pm S E$, covariate $54.43 \pm 0.47$, treatment $56.81 \pm 0.46$ vs control $55.01 \pm 0.46), F_{(1,29)}=11.81, P<0.01$ were significantly higher in both winter and summer season in goats. Neutrophil \& eosinophil count were found non-significant compared to control group.

\section{Effect of M.pruriens supplementation on serum biochemical parameters-}

Values of serum biochemical parameters have been graphically represented in Fig. 3. Total protein(Mean \pm SE; covariate $6.29 \pm 0.04$, treatment $6.42 \pm 0.04$ vs control $6.27 \pm 0.04 \mathrm{~g} / \mathrm{dl}$ ), $\mathrm{F}_{(1,29)}=$ $12.61, P<0.01$ and albumin (Mean $\pm \mathrm{SE}$; covariate $2.60 \pm 0.04$, treatment $2.67 \pm 0.02$ vs control $2.62 \pm 0.02$ $\mathrm{g} / \mathrm{dl}), \mathrm{F}_{(1,29)}=8.69, P<0.01$ levels were significantly increased in both the seasons. Significantly high value of globulin (Mean \pm SE; covariate $3.65 \pm 0.06$, treatment $3.71 \pm 0.04$ vs control $3.58 \pm 0.04 \mathrm{~g} / \mathrm{dl}$ ), $\mathrm{F}_{(1,13)}=$ $6.02, P<0.05 \&$ triglycerides (Mean $\pm S E$; covariate $23.63 \pm 0.79$, treatment $25.67 \pm 0.72$ vs control $23.29 \pm$ $0.72 \mathrm{mg} / \mathrm{dl}), \mathrm{F}_{(1,13)}=5.38, P<0.05$ was found in does during summer season. Effect of lowering of creatinine (Mean $\pm \mathrm{SE}$; covariate $0.84 \pm 0.01$, treatment $0.79 \pm 0.01 \mathrm{vs}$ control $0.88 \pm 0.01 \mathrm{mg} / \mathrm{dl}), \mathrm{F}_{(1,29)}=$ $12.81, P<0.01 \&$ BUN (Mean \pm SE; covariate $20.76 \pm 0.27$, treatment $19.42 \pm 0.18$ vs control $20.64 \pm 0.18$ $\mathrm{mg} / \mathrm{dl}), \mathrm{F}_{(1,29)}=21.71, \mathrm{P}<0.01$ level was significant in $M$. pruriens supplemented does in both season. Significant hypochoesteremic effect was observe in M. pruriens supplemented does (Mean \pm SE; covariate $87.03 \pm 0.69$, treatment $83.14 \pm 0.53$ vs control $85.61 \pm 0.53), F_{(1,29)}=6.43, P<0.05$. ALT, AST levels difference were non-significant. Significant increase in overall ALP level (Mean \pm SE; covariate $31.29 \pm 0.48$, treatment $32.18 \pm 0.37 \mathrm{vs}$ control $31.18 \pm 0.42 \mathrm{U} / \mathrm{L}), \mathrm{F}_{(1,29)}=7.30, \mathrm{P}<0.05$ was observed in $M$. pruriens supplemented does.

\section{Effect of M.pruriens supplementation on oxidative stress and antioxidant parameters-}

Values of oxidative stress and antioxidant assay parameters have been graphically represented in Fig. 4. Lipid peroxidation (MDA) level (Mean \pm SE; covariate $180.67 \pm 2.11$, treatment $169.59 \pm 1.88$ vs control $180.52 \pm 1.88 \mathrm{nmol} / \mathrm{g}$ of $\mathrm{Hb}), \mathrm{F}_{(1,29)}=16.69, \mathrm{P}<0.01$ were significantly decreased, while $\mathrm{GSH}$ (Mean $\pm \mathrm{SE}$; covariate $3.47 \pm 0.08$, treatment $3.92 \pm 0.07$ vs control $3.45 \pm 0.07 \mu \mathrm{mol} / \mathrm{g}$ of $\mathrm{Hb}), \mathrm{F}_{(1,29)}=20.77, \mathrm{P}<0.01$ \& TAC level (FRAP value)(Mean \pm SE; covariate $7.09 \pm 0.11$, treatment $7.45 \pm 0.12 \mathrm{vs}$ control $7.21 \pm 0.12 \mu \mathrm{mol} / \mathrm{ml}$ ), $F_{(1,29)}=12.03, P<0.01$ were significantly increased during both seasons in $M$. pruriens supplemented does compare to control group while no significant effect on SOD level was found.

\section{Effect of M.pruriens supplementation on plasma total Immunoglobulin-}

Values of plasma immunoglobulin levels have been graphically represented in Fig. 5. Significant increase in plasma total immunoglobulin level (Mean \pm SE; covariate $17.95 \pm 0.47$, treatment $19.00 \pm 0.30$ vs control $18.36 \pm 0.30 \mathrm{mg} / \mathrm{ml}), \mathrm{F}_{(1,13)}=7.09, \mathrm{P}<0.05$ were found in $M$. pruriens supplemented group during the summer season. 


\section{Effect of M.pruriens supplementation on thyroid hormones Profile-}

Thyroid hormone estimation by ELISA were done on day 0 and day 30 plasma samples. Values of T3 and T4 hormones have been graphically represented in Fig. 5. Data for thyroid profile was analyzed by univariate ANCOVA using day 30 as a dependent variable, group as a fixed factor, and day 0 as a covariate. The decrease in plasma T3 level was non-significant, while plasma Thyroxin (T4) level was significantly decreased in $M$. pruriens supplemented group. Effect was highly significant during summer season (Mean \pm SE; covariate $60.53 \pm 0.23$, treatment $59.21 \pm 0.34$ vs control $60.56 \pm 0.34 \mathrm{ng} / \mathrm{ml}), \mathrm{F}_{(1,15)}=$ $13.77, P<0.01$ \& in winter $F_{(1,15)}=5.13, P<0.05$.

\section{Effect of M.pruriens supplementation on plasma progesterone levels-}

Plasma progesterone were estimated during day 0,10 and 20th day of estrous cycle appearing after 15 days of feeding and data was analyzed by repeated measure ANOVA. Values of plasma progesterone levels have been graphically represented in Fig. 5. Significantly higher overall (Mean \pm SE, treatment $2.138 \pm 0.03$ vs control $2.026 \pm 0.029 \mathrm{ng} / \mathrm{ml}), \mathrm{F}(1,30)=6.39, \mathrm{P}<0.05$ overall plasma progesterone level was found in the $M$ pruriens supplemented group compared to the control group. The effect was highly significant during winter season (Mean \pm SE, treatment $2.214 \pm 0.016$ vs control $2.091 \pm 0.027$ $\mathrm{ng} / \mathrm{ml}), \mathrm{F}_{(1,14)}=15.40, \mathrm{P}<0.01$ but the effect was found non-significant in does during summer season. Reproductive parameters conception rate, fertility rate, prolificacy, and fecundity did not differ significantly between group. No undesirable effect was observed over reproductive performance.

\section{Discussion}

Changes observed due to $M$. pruriens supplementation, particularly in the summer season, were Significantly decreased heart rate, blood glucose, creatinine, blood urea nitrogen, MDA lipid peroxidation, T4 level. Increase in TLC, lymphocyte \%, monocyte \%, total proteins, albumin, ALP, reduced glutathione, total antioxidant capacity, total immunoglobulin levels. Khan \& Kumar (2017) reported that M. pruriens possesses antihypertensive properties. Extract of $M$. pruriens showed a time and dose-dependent decrease in mean arterial pressure in rats. Higher PCV, $\mathrm{Hb}$, and TEC levels in $M$. pruriens supplemented group may be because of lowered Erythrocytic lipid peroxidation observed in the MDA assay, thus lowering the impact of the oxidative attack on RBCs. In a similar finding, Rajaram and Janardhanan (1991) reported that there was a significant difference in WBC total count for rats administered with $M$. Pruriens compared with the control. Creatinine \& BUN level decrease may be due to the positive anabolic effect of $M$. pruriens supplementation on muscle \& protein metabolism, respectively. In a similar finding, Concessao et al. (2020), studied the protective effect of M. pruriens seed against arsenic-induced kidney dysfunction in rats. A decrease in the levels of kidney function parameters (creatinine and urea) in serum was observed in animals treated with M. pruriens $(350 \mathrm{mg} / \mathrm{kg}$ body $w \mathrm{t}, 530 \mathrm{mg} / \mathrm{kg}$ body wt, and 700 $\mathrm{mg} / \mathrm{kg}$ body weight). Hypochoesteremic effect reported by Oloruntola et al. (2018) in rabbits fed on a diet with $M$. pruriens supplementation had lower cholesterol level compared to those rabbits fed on the control diet. They suggested that saponins in the $M$. pruriens seeds may be linked to the reduction of 
cholesterol uptake in the gut. Flavonoids and tannins contents of the seed have been recognized as the major phenolic compounds acts as a antioxidant to scavenge free radicals or ROS (Poltterait,1997). The increase in the level of GSH \& other non-enzymatic antioxidants in goats may indicate the antioxidant potential of $M$. pruriens seed to neutralize the toxic effect of ROS. Higher immunoglobulin levels were in agreement with findings reported by Yousaf et al. (2017) that M pruriens extract in the albino rat in which improved neutrophil function and higher immunoglobulin were found with $M$ prurien extract. Dopamine \& L-DOPA inhibits TSH-stimulated T4 release through both adrenergic and dopaminergic receptors has been reported by Mayyan et al. (1986). Increased levels of progesterone may be attributed to an increase in luteinizing hormone level after estrous in beetal does. Studies have shown that L-DOPA stimulates the secretion of gonadotropin-releasing hormone $(\mathrm{GnRH})$, which in turn stimulates the secretion of FSH and $\mathrm{LH}$ hormones from the anterior portion of the pituitary gland responsible for the increase in progesterone (Singh et al. 2013). Serum level of follicle-stimulating hormone, testosterone, luteinizing hormone, testicular antioxidant defense, and reduction in oxidative stress has been reported in male albino rat fed with $0.75 \mathrm{~g} \mathrm{M}$. pruriens seed powder (Temitop et al., 2014). In Does, positive anabolic effect is found in terms of reduction in creatinine, BUN \& cholesterol levels, improvement in antioxidant profile, plasma progesterone level which is associated with an increase in health \& reproductive efficiency of does. Thus it may be concluded that Supplementing M. pruriens @ 100mg/kg body weight to goats delivered several health beneficial effects like increasing antioxidant level, \& immunoglobulin level, improving hematological \& liver function profile, increasing mitochondrial respiration efficiency, thus improving overall physiological adaptability of goats to seasonal stress.

\section{Declarations}

Funding - Institutional funding

Conflicts of interest/Competing interests -The authors have no relevant financial or non-financial interests to disclose.

Ethics approval - All the experimental protocols using animals have been approved by the Institutional animal ethical committee (IAEC) of the Guru Angad Dev Veterinary and Animal Sciences University, Ludhiana (Punjab), India, and by CPCSEA, New Delhi vide reference letter V-11011(13)/2/2020-CPCSEADADF dated 10/02/2020. All the experiments were carried out according to the guidelines of the CPCSEA.

Consent to participate - Not applicable.

Consent for publication - Not applicable.

Informed consent- Not applicable

Availability of data and material - All data are available via the corresponding author.

Code availability - Not applicable. 
Authors' contributions- All authors contributed to the study conception and design. Material preparation, data organization, and analysis were performed by Sameer N. Jadhav. The first draft of the manuscript was written by the first author and all authors commented on previous versions of the manuscript. All authors read and approved the final manuscript.

Acknowledgement-Author wants to thank Dean PGs GADVASU for providing necessary facilities for conduction of research work

\section{References}

1. Benzie, I. F., \& Szeto, Y. T. (1999). Total antioxidant capacity of teas by the ferric reducing/antioxidant power assay. Journal of agricultural and food chemistry, 47(2), 633-636.

2. Concessao, P., Bairy, L. K., \& Raghavendra, A. P. (2020). Protective effect of Mucuna pruriens against arsenic-induced liver and kidney dysfunction and neurobehavioral alterations in rats. Veterinary world, 13(8), 1555.

3. Daromala J, John A and Olusiji S.2015. Effect of Mucuna on spermiogram of west African dwarf buck. Tropical \& Subtropical Agrosystem,1: 192-96.

4. Drabkin, D. L., \& Austin, J. H. (1935). Spectrophotometric studies. J. biol. Chem, 112, 51-65.

5. Ellman G. L. (1959). Tissue sulfhydryl groups. Archives of biochemistry and biophysics, 82(1), 7077.

6. IBM Corp. Released 2013. IBM SPSS Statistics for Windows, Version 22.0. Armonk, NY: IBM Corp.

7. Khan, M. Y., \& Kumar, V. (2017). Mechanism of the antihypertensive effect of Mucuna pruriens L. seed extract and its isolated compounds. Journal of Complementary and Integrative Medicine, 14(4).

8. Lowry, O.H., Rosebrough, N.J., Farr, A.L., Randall, R.J. (1951). Protein measurement with the folinphenol reagents. Journal of Biological Chemistry. 193, 265-275.

9. Maayan, M. L., Volpert, E. M., \& Sellitto, R. V. (1986). Dopamine and L-DOPA, precursors of norepinephrine: effects on thyroxine release. In Frontiers in Thyroidology (pp. 303-306). Springer, Boston, MA.

10. Misra, L., \& Wagner, H. (2007). Extraction of bioactive principles from Mucuna pruriens seeds.Indian Journal of Biochemistry \& Biophysics 44,54-56.

11. Misra, R. P., \& Puneet, K. (2009). Improved shelter management, feeding and watering devices for goats. Goat enterprises, CIRG, Mathura (UP), India, 132.

12. Natarajan, K., Narayanan, N., \& Ravichandran, N. (2012). Review on "Mucuna"-The wonder plant. Int J Pharm Sci Rev Res, 17(1), 86-93.

13. Nishikimi, M., Rao, N. A., \& Yagi, K. (1972). The occurrence of superoxide anion in the reaction of reduced phenazine methosulfate and molecular oxygen. Biochemical and biophysical research communications, 46(2), 849-854. 
14. Oloruntola, O. D., Ayodele, S. O., Adeyeye, S. A., \& Agbede, J. O. (2018). Performance, haematobiochemical indices and antioxidant status of growing rabbits fed on diets supplemented with Mucuna pruriens leaf meal. World Rabbit Science, 26(4), 277-285.

15. Oser, B. L. (1965). Blood and other body fluids. Oser BL (ed), 321-67.

16. Placer, Z. A., Cushman, L. L., \& Johnson, B. C. (1966). Estimation of product of lipid peroxidation (malonyl dialdehyde) in biochemical systems. Analytical biochemistry, 16(2), 359-364.

17. Polterait, O. (1997). Antioxidants and free radical scavengers of natural origin. Current organic chemistry, 1(4), 415-440.

18. Rajaram, N., \& Janardhanan, K. (1991). The biochemical composition and nutritional potential of the tribal pulse, Mucuna gigantea (Willd) DC. Plant Foods for Human Nutrition, 41(1), 45-51.

19. Ribeiro, M. N., Ribeiro, N. L., Bozzi, R., \& Costa, R. G. (2018). Physiological and biochemical blood variables of goats subjected to heat stress-a review. Journal of Applied Animal Research, 46(1), 1036-1041.

20. Rojas-Downing, M. M., Nejadhashemi, A. P., Harrigan, T., \& Woznicki, S. A. (2017). Climate change and livestock: Impacts, adaptation, and mitigation. Climate Risk Management, 16, 145-163.

21. Saleh, M. A. (2009). Erythrocytic oxidative damage in crossbred cattle naturally infected with Babesia bigemina. Research in Veterinary Science, 86(1), 43-48.

22. Singh, A. P., Sarkar, S., Tripathi, M., \& Rajender, S. (2013). Mucuna pruriens and its major constituent L-DOPA recover spermatogenic loss by combating ROS, loss of mitochondrial membrane potential and apoptosis. PloS one, 8(1), e54655.

23. Temitope N, Ojo, Gbotolorun, Stella, Oremosu and Ademola. 2014. Fertility Enhancing Potential of Mucuna pruriens Seeds in Female Sprague-Dawley Rats. British Journal of Medicine and Medical Research 4: 3148-57.

24. Tucker C B. Rogers A R and Schutz K E 2008. Effect of solar radiation on dairy cattle behaviour, use of shade and body temperature in a pasture-based system.Applied Animal Behaviour Science 109: 141-154.

25. Yousaf, F., Shahid, M., Riaz, M., Atta, A., \& Fatima, H. (2017). Immunomodulatory potential of Anacyclus pyrethrum (L.) and Mucuna pruriens (L.) In male albino rats. Journal of biological regulators and homeostatic agents, 31(2), 425-429.

26. Zhang, Chen \& Bruins, Marieke \& Yang, Zhi-qiang \& Liu, Shu-Tao \& Rao, Ping-Fan. (2016). A new formula to calculate activity of superoxide dismutase in indirect assays. Analytical Biochemistry. 503. 10.1016/j.ab.2016.03.014.

\section{Figures}




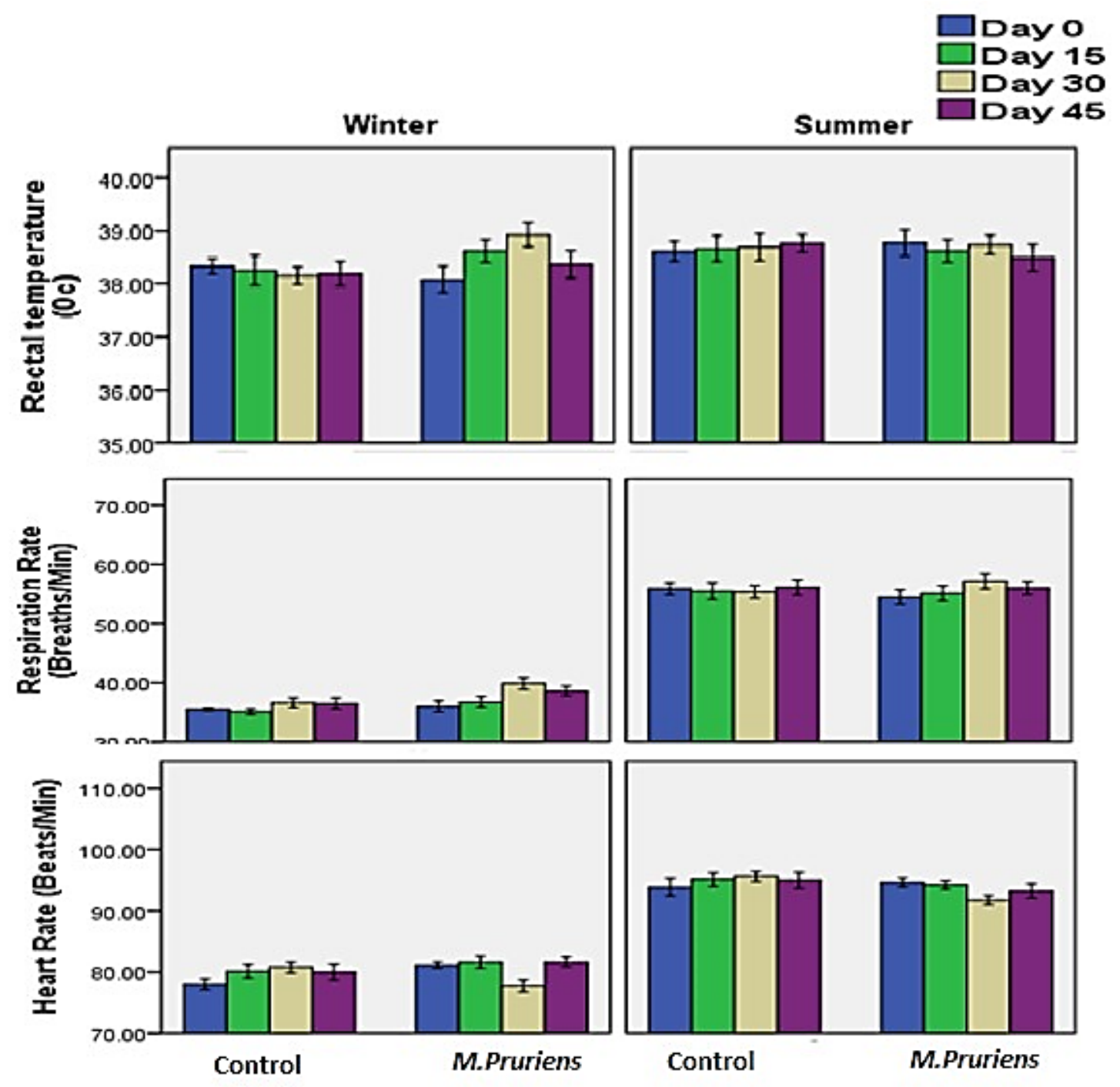

Figure 1

Effect of M.pruriens supplementation on physiological parameters (Mean \pm SE). 


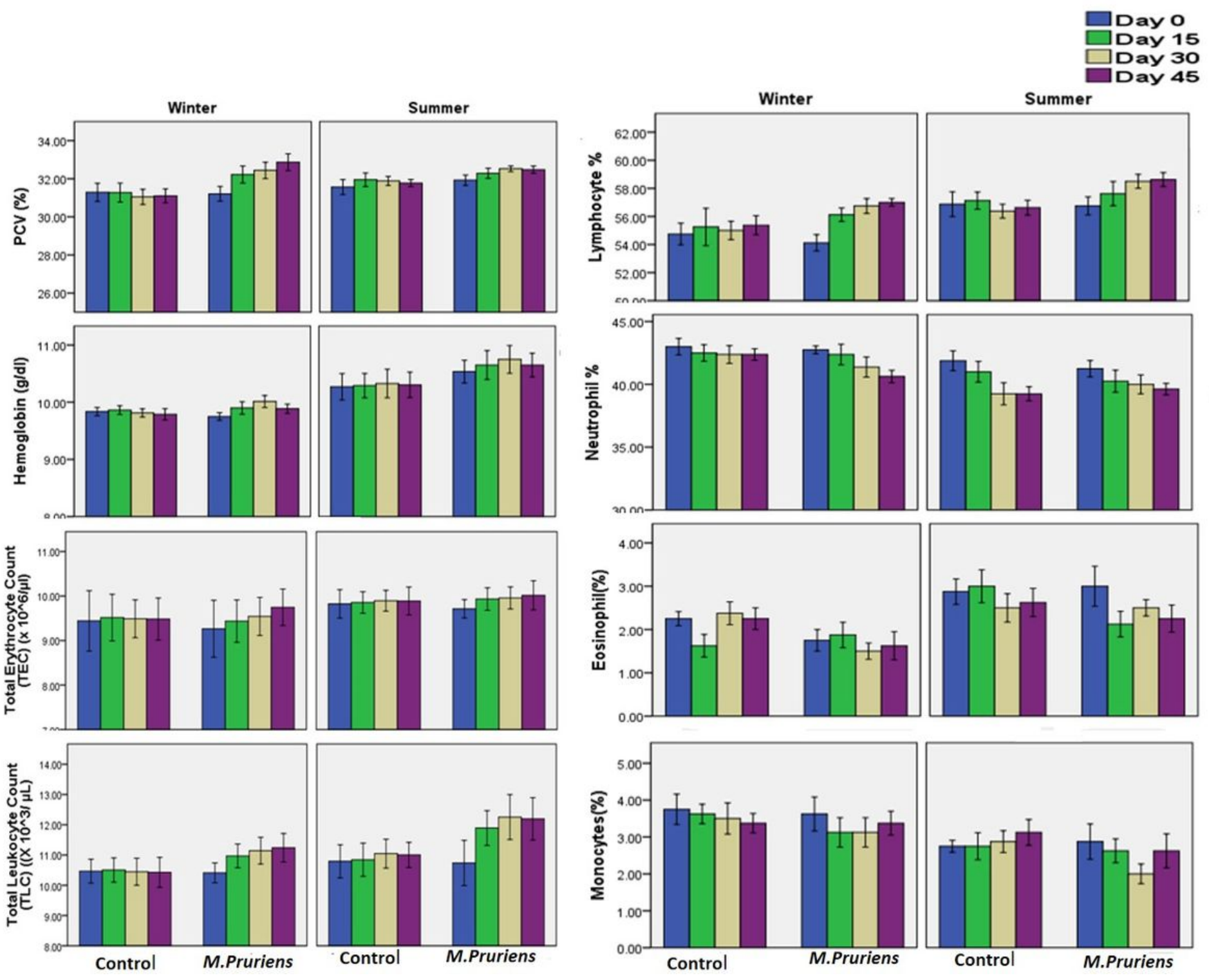

Figure 2

Effect of M.pruriens supplementation on hematological parameters (Mean \pm SE). 

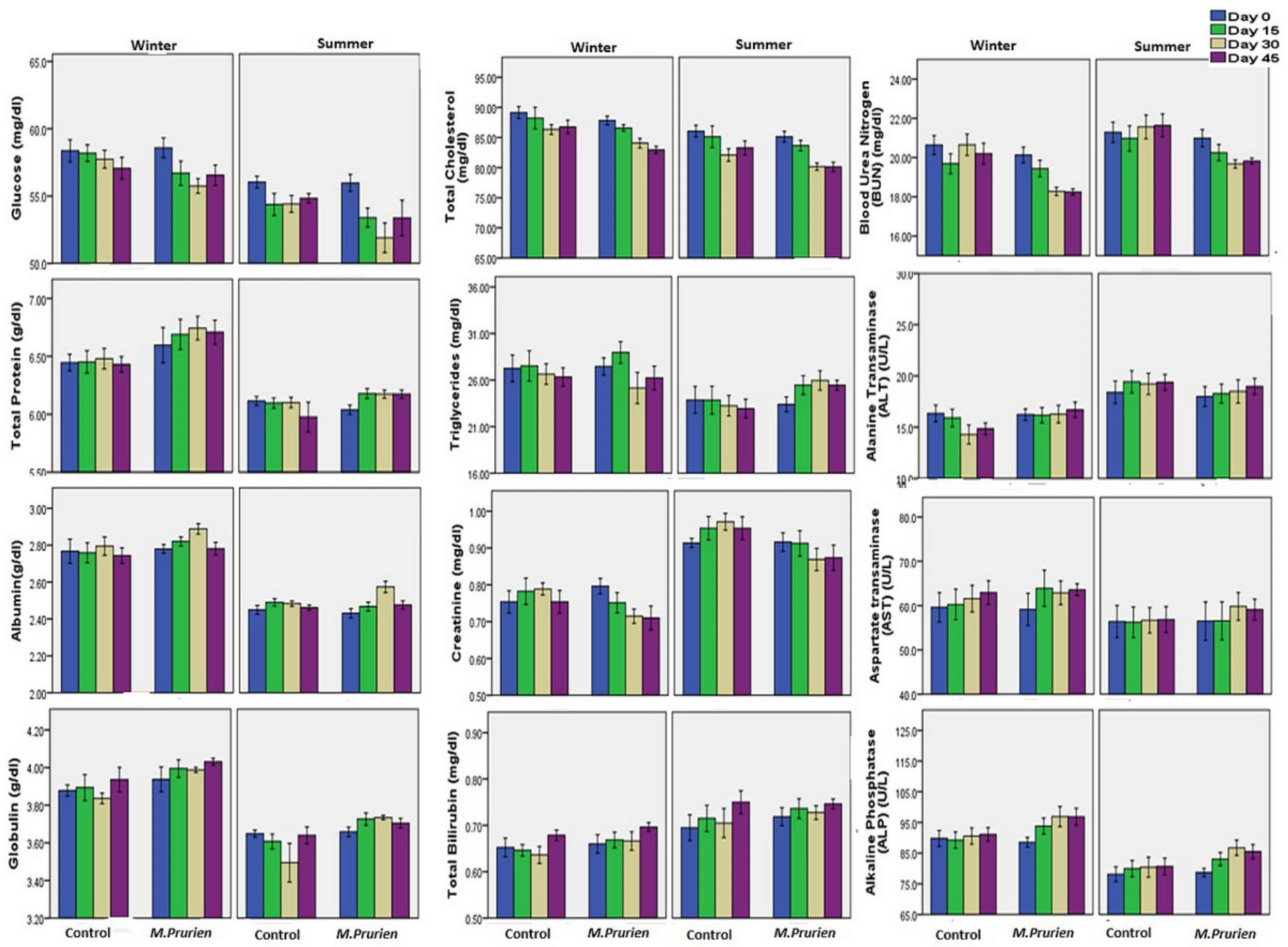

Figure 3

Effect of M.pruriens supplementation on Serum biochemical parameters (Mean \pm SE). 


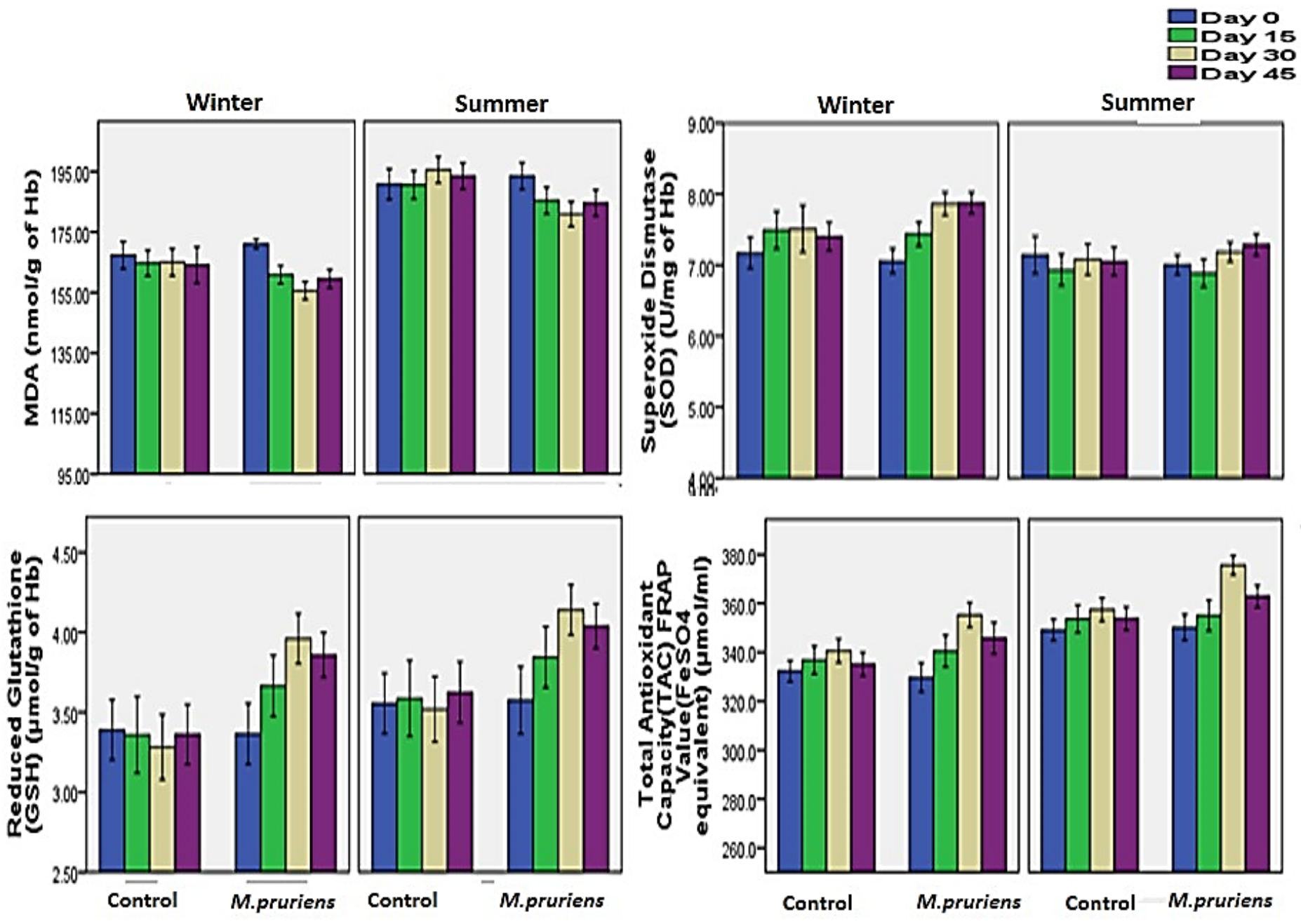

Figure 4

Effect of M.pruriens supplementation on oxidative stress and antioxidant parameters (Mean $\pm \mathrm{SE}$ ). 


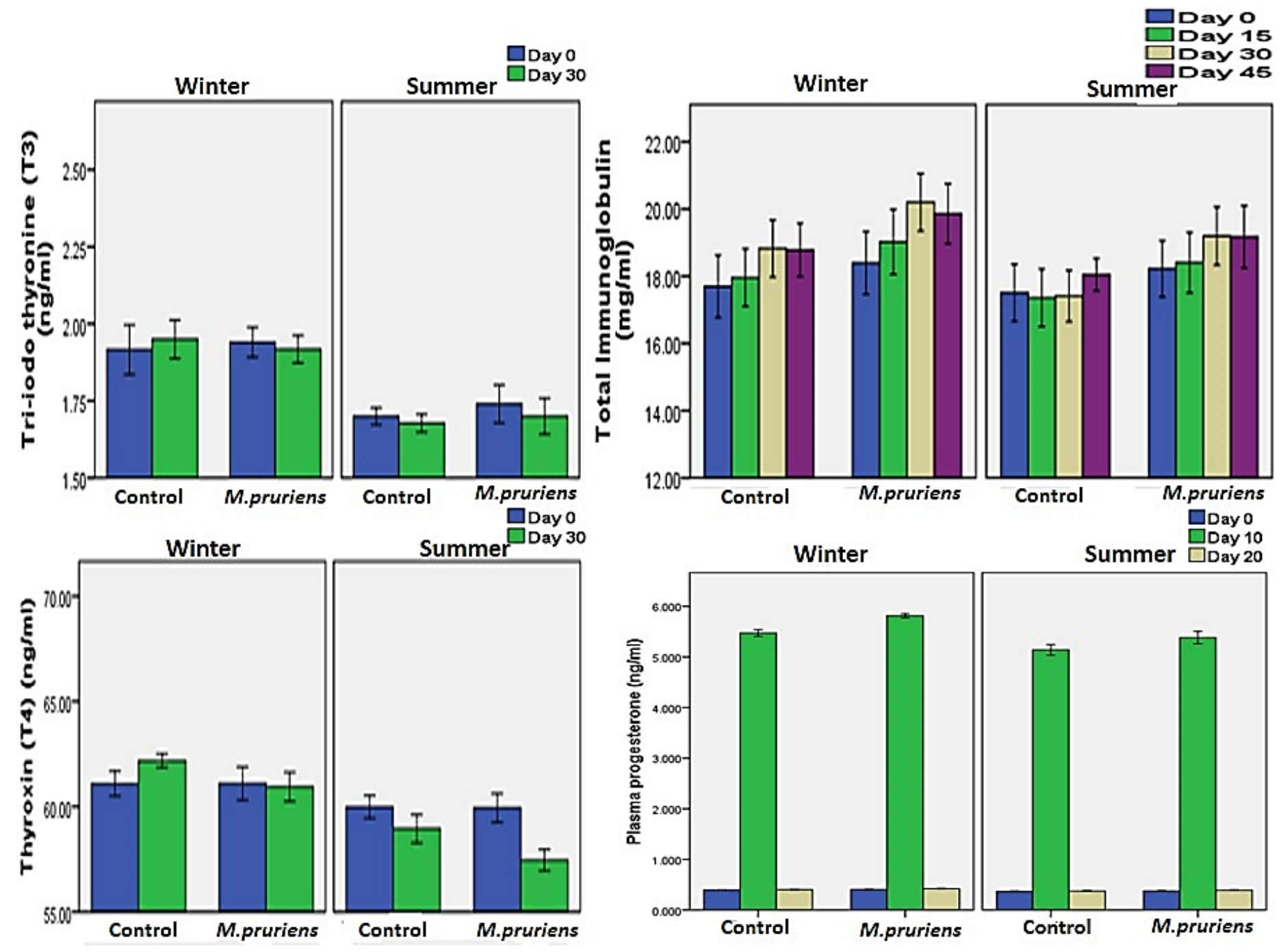

Figure 5

Effect of M.pruriens supplementation on T3, T4, plasma progesterone and total immunoglobulin (Mean \pm SE) levels. 